\title{
Leader-Member Exchange and Relational Quality in a Singapore Public Sector Organization
}

\section{Ms. Mabel Yeo}

Singapore Public Sector

10 Tanah Merah Besar Road

Singapore 498834

Tel: +65 65469423

Fax: +65 65468306

Email: mfwyeo@gmail.com

\section{And}

\section{Dr. Subramaniam Ananthram}

Senior Lecturer - International Business

Curtin Business School, Curtin University

Kent Street

Bentley, Western Australia 6102

Australia

Tel: +61 892661312

Fax: +61 892667897

Email: S.Ananthram@curtin.edu.au

\section{Professor Stephen Teo}

Professor of Human Resource Management

Department of Management

AUT Business School, AUT University

Auckland, 1142, New Zealand

Email: Stephen.teo@aut.ac.nz

\section{Dr. Cecil Pearson}

Senior Research Fellow

Curtin Business School, Curtin University

Kent Street

Bentley, Western Australia 6102

Australia

Tel: +61 892661340

Fax: +61 892667897

Email: C.Pearson@curtin.edu.au 


\title{
Leader-Member Exchange and Relational Quality in a Singapore Public Sector Organization
}

\begin{abstract}
An objective of Singapore's on-going public sector reform (PS21) requires agencies to focus on getting the best out of its employees. One way of doing this is by creating a positive leadermember exchange (LMX) relationship, enabling supervisors to motivate their subordinates towards the development of organizational citizenship behaviours (OCB). This paper reports the extent of LMX and relational quality in a public sector agency experiencing PS21 reform and high staff turnover. In addition, we examined the effects of organisational justice perceptions and job satisfaction towards a subordinates' OCB. A path model was developed to examine the relationships between LMX, organisational justice, job satisfaction and OCB and tested by applying LMX theory. The path analysis results showed that LMX mediates the relationship between organisational justice perceptions and OCB. The results also showed that one's job satisfaction led to higher level of OCB. The study findings have implications for theory and practice which are presented in the discussion section.
\end{abstract}

Keywords: public sector, PS21, organizational citizenship, job satisfaction, organizational justice, leader member exchange, Singapore 


\section{INTRODUCTION}

Singapore has a history of administrative reforms within the public sector. The themes of the administrative reforms in Singapore have changed considerably from the 1960s and 70s where the focus was on 'survival' and 'efficiency' respectively; to the 1980s when the focus shifted to 'people' and attracting the right talent into the public sector (Commonwealth Secretariat 1998).

In the 1990s, the Singaporean government initiated the "Public Service for the $21{ }^{\text {st }}$ Century" (also known as PS21) reforms to marshal 'change' and lead Singapore into an uncertain future (Commonwealth Secretariat 1998). PS21 represents an agenda for the public service to lead the national and the private sector for excellence (Cheung and Scott 2003). As noted by Lee and Haque (2006: 615), the implementation of PS21 reforms by the Singapore government aims "to create a public sector which has a different organisational culture, which emphasizes high standard of service, transforming managerial mindsets, creation of a new bureaucratic culture which is client centred, and emphasizes service excellence". Saxena (2011) further explained that the PS21 reforms were ambitious and required the public service to harness the creativity and commitment of its people, and become leaner, more responsive, and more service oriented.

In this context, PS21 reforms is unique, in that, unlike the New Public Management (NPM) rhetoric in a number of OECD countries (for example, USA and Canada) which implicitly denigrates public sector effectiveness and advocates increased involvement of private sector leadership, privatisation and outsourcing (OECD, 2010), PS21 reform "seeks to maintain and further strengthen the public service as a leading institution of meritocratic excellence" (Cheung and Scott 2003: 155). While NPM was about 'managerialism' (Pollitt 1993) and 'entrepreneurial government' (Osborne and Gaebler 1992), PS21 incorporated a higher and more visionary plane with a central underpinning to completely change the culture of the public service and to 
transform it from "reactivity to proactivity, and, from a satisfaction of the present to a questioning of the future" (Lim 1998: 126). It should also be noted that PS21 reforms, as compared with the ones implemented earlier in Singapore, place more emphasis on leadership and process (Ong 2010) rather than on the more mundane managerialist notions of efficiency and effectiveness in service delivery (Cheung and Scott 2003). Lim (1998: 131) explained that PS21 reforms were about "leadership rather than management". Lee and Haque (2006) supported the importance of leadership quality in bringing about a change in the administrative culture of the Singapore public service sector as part of the PS21 reforms. A key aspect of leadership and relational quality in implementing these new public management related reforms is the role of supervisor-subordinate relationships. In this context, the leader member exchange (LMX) theory (Dienesch and Liden 1986; Graen and Uhl-Bien 1995; Lee 2005) provides the theoretical frame for the current study as public sector reforms have been claimed to aim at "curbing the power of employees, increasing managerial prerogative and accountability" (Ackroyd et al. 2007: 18). The quality of the leaderfollower relationship plays an important part in managing the job satisfaction of public sector employees (Brunetto et al. 2010), especially in Singaporean public sector agencies as senior management introduces managerial reform in the hope of changing the bureaucratic culture.

LMX theory describes how leaders develop different working relationships with their subordinates depending on the quality of their workplace relationship (Graen 1976; Brunetto et al. 2010) Specifically, LMX theory posits that there are many benefits of high quality leadermember exchange (Scandura and Graen, 1984; Crouch and Yetton, 1988; Erdogan et al. 2006; Pellegrini and Scandura 2006; Vigoda-Gadot 2007). Parry (2003) noted that leadership styles can have an effect on innovation and overall effectiveness within public sector organisations. These high quality exchanges have been related to increased trust, interaction, commitment, willingness 
to contribute, support and rewards (Dienesch and Liden 1986; Gerstner and Day 1997; Stringer 2006; Erdogan and Enders, 2007). These exchanges lead to positive OCB (Moorman 1991; Ishak 2005). Wang et al. (2005) suggested the LMX theory was an appropriate lens for explaining the link between leader-member exchange, organizational performance and OCB.

There has been considerable research which considers OCB (Moorman 1991; Schappe 1998) as the discretionary behaviour beyond job requirements that is not explicitly recognized through the organization's reward structure (Organ 1988). Research has shown that OCB is important in the public sector (Coyle-Shapiro and Kessler 2003). We argue that OCB and its components, namely, loyalty, compliance and participation (Van Dyne et al. 1994) are vital for Singapore's public sector organizations as increasing emphasis is being placed on the provision of high quality service culture, commonly found in public sector agencies undergoing the PS21 reform (Lee and Haque 2006).

High quality exchange relationship between leaders and subordinates has been found to result in higher OCBs in subordinates which lead to higher quality work (Podsakoff et al. 1990; Moorman 1991). Researchers have argued that OCB can be encouraged through LMX (Liden and Graen 1980; Bolino 1999; Bhal 2006) as it enhances employees' contribution towards organizational performance. OCB can also be encouraged through job satisfaction (e.g., Organ 1988; Moorman 1991), LMX (e.g., Liden and Graen 1980), and organizational justice perceptions (Moorman 1991; Bhal 2006). It is important to note that while these relationships are established in the literature, most of the studies did not examine leadership and OCB in the context of the public sector in Singapore (with the exception of Ang et al. 2003). 
The current study develops and empirically tests a path model to examine the relationships between LMX, organizational justice perceptions, OCB and job satisfaction in a public sector organization in Singapore. As discussed earlier, LMX as a vital aspect of reforming the public sector via changes to the relationship between leaders and their subordinates. LMX theory is relevant for this particular organisation because of the underlying features of the Singapore civil service, which emphasises meritocracy, pragmatism and integrity (Yiannouka, 2011). PS21 is about change and improvement and it requires every public service employees to be an agent of change (PS21, 2010). Together with the adoption of employee engagement and leadership in the Singapore civil service (Ong, 2010), the application of LMX theory is relevant for the current study as the theory draws upon the concept of workplace relationships, employee performance and job satisfaction as the key variables in the current study.

The linkages between the assessed variables have significant theoretical and practical implications. A contribution of the current study is the development and empirical testing of a theoretical framework which includes organisational justice, job satisfaction, LMX and OCB by using the LMX theoretical lens to empirically test the linkages in a relatively untested national context - Singapore. The main practical implication of the study is evidence of the critical role of LMX in fostering increased levels of job satisfaction and OCB. Based on the findings, it is posited that LMX can be an avenue for leveraging better leader-subordinate relationships and ultimately, performance, in a Singaporean public sector organisation. It is argued that in light of Singaporean public sector's on-going implementation of PS21 type reforms, there is an increasing need for effective leadership in helping transform its organisational structure to be leaner and its organisational culture to be more dynamic. A detailed explanation of the theoretical and practical implications of the study findings is presented in the Discussion section The 
literature review is presented next followed by an explanation of the research design and the findings of the causal path model.

\section{LITERATURE REVIEW}

Organizational leadership theory has examined leadership in the context of LMX. Dansereau et al. (1975) found that certain groups of employees enjoy higher levels of exchange with their managers and receive greater responsibility, more feedback, and personal attention than others. Dansereau et al. (1975) contend that managers often single out these employees to hold greater responsibility because they are accountable for the effectiveness of their work units. In addition, grooming a group of employees whom leaders can rely on to assist them is advantageous; a model of leadership which is supported by Liden and Graen (1980). Engle and Lord (1997) reported leaders who expected their subordinates to reach higher levels in their organizations were more likely to engage in high quality LMX.

LMX theory describes how leaders develop different working relationships with their subordinates depending on the quality of their workplace relationship (Brunetto et al. 2010). According to LMX theory, subordinates that a supervisor likes and trusts seek more attention, favours and supportive decision-making characterised by 'in-group' behaviour (Gerstner and Day 1997). Graen and Uhl-Bien (1995) noted that this may lead to tangible benefits such as promotions and bonuses, and/or intangible benefits such as interesting work assignments and greater control over workloads. Lee (2005: 656) summarised that "in general, these dyadic exchanges are thought to range on a continuum from high to low". Dienesch and Liden (1986) add that these high quality exchanges were characterised by greater levels of trust, interaction, support and rewards than low quality exchanges. 
These exchanges lead to positive OCB (Moorman 1991; Ishak 2005). OCB elicits voluntary contributions by employees and is a vital tool for public sector organizations (Vigoda 2000; Vigoda and Cohen 2003). These informal contributions enhance overall organization effectiveness (Organ and Konovsky 1989). Furthermore, employee attitudes and leader behaviours appear to be more strongly related to OCB than other antecedents (Podsakoff et al. 2000). For example, Liden and Graen (1980), Bolino (1999) and Bhal (2006) reported that a harmonious leader-subordinate relationship led to positive organizational citizenship behaviours among subordinates, thereby demonstrating a clear link between OCB and organizational leadership. This relationship has been further empirically verified by Moorman (1991) Ishak (2005) and Brunetto et al (2010). It has also been posited that LMX could have a mediating impact on OCB in a public sector sample (Materson et al. 2000) and a private sector sample (Liang et al. 2007).

As organizational leaders constantly battle to maximise employee potential as a source of continued competitive advantage, they are constantly searching for ways to motivate employees to engage in suitable behaviours to achieve organizational goals and objectives (Teagarden and Von Glinow 1997). Coyle-Shapiro (2002) affirmed that an organizations' (leaders') ability to do so lies in its ability to fulfil employees' perception and expectations of the organization. CoyleShapiro and Kessler's (2003) research in a public sector sample showed that the required positive behaviours from public sector employees can be created by ensuring that they reciprocate the treatment they received from their supervisors. This perception with regard to how an employee judges the behaviour of the organization and their resulting attitude and behaviour that comes from this is referred to as organizational justice (Greenberg 1987). A number of studies have 
reported the link between justice perceptions, OCB and employee performance outcomes (Organ 1988; Moorman 1991).

Researchers have argued that OCB can be encouraged through job satisfaction (Organ 1988; Moorman 1991; Schappe 1998), LMX (Liden and Graen 1980; Bolino 1999; Bhal 2006), and organizational justice perceptions (Moorman 1991; Skarlicki and Latham, 1996; Bhal 2006) to enhance employee contribution towards organizational performance. Central to this argument is the contention that a harmonious supervisor-subordinate relationship can influences employees' perceptions towards support from the organization and consequently improve their morale and commitment, thereby reducing employee turnover (Brunetto et al. 2010). A study by Materson et al (2000) concluded that LMX mediated the relationship between justice and job satisfaction as well as OCB with public university employees. Using this literature, the study develops a causal conceptual framework (see Figure 1). A discussion on the postulated hypotheses that are presented as arrow headed lines in Figure 1 is presented next.

Insert Figure 1 about here

\section{Hypotheses Development}

\section{Perceptions of Organizational Justice and Job Satisfaction}

It has been suggested that this fairness or 'justice' can be treated as an organizational variable with numerous positive outcomes (Greenberg 1990; Skarlicki and Latham 1996). Employees' perceptions of organizational justice affect their attitudes towards their employer and management, the degree of trust in their supervisor and their levels of commitment (Folger and Konovsky 1989). Equity theory proposes that employees react adversely to perceived unfairness 
by engaging in retaliatory behaviour detrimental to organizational functioning (Skarlicki and Folger 1997). These behaviours include withholding performance, absenteeism, theft and sabotage.

The three dimensions of organizational justice: procedural, distributive and interactional (Folger and Corparanzo 1998), relate to different employee attitudes and behaviours (Stinglhamber et al. 2006). Procedural justice relates to employees' perceptions about the fairness of the process and procedures used to arrive at decisions (Rubin 2007); distributive justice relates to the manner in which outcomes are disbursed in the organization (Wharton et al. 2004); and interactional justice is the interpersonal sensitivity with which an individual is treated and the sincerity with which procedures are applied in decision making (Folger and Corparanzo 1998). Although the three components are independent, they are correlated. Skarlicki and Folger (1997) demonstrated that if distributive justice was low, disgruntled employees are more likely to react negatively towards management unless the situation was moderated by high procedural or interactional justice (Skarlicki and Folger 1997). Thus, an employee's perception of organizational justice is expected to relate to their job satisfaction.

Organ (1988) noted that job satisfaction can be viewed as an attitude that employees' hold about their job. Moorman (1991) explained that this attitude could have developed through the employees' perceptions of fairness. Fischer (2004) concluded that job satisfaction is strongly related to distributive justice. From an employee's perspective, job satisfaction is about having his/her needs and wants met (Lambert 2003). Moreover, Petty et al. (1984) found that performance causes satisfaction or underperformance causes dissatisfaction. The researchers contend that, "...if the employee perceives the consequences of performance as inequitable, the 
dissatisfaction that results may cause a future reduction in effort, which will lower performance" (1984: 719). Lambert (2003) conducted a study on the impact of justice on correctional staff and found that both procedural and distributive justice were important contributors to job satisfaction across a cross-section of staff at varying positions. Hence, we hypothesized that

Hla: Employees' perceptions of procedural justice have a positive effect on their levels of job satisfaction.

H1b: Employee's perceptions of distributive justice will have a positive effect on their levels of job satisfaction.

H1c: Employee's perceptions of interactional justice will have a positive effect on their levels of job satisfaction.

\section{Perceptions of Organizational Justice and LMX}

LMX is positively related to employees' equity perceptions (Vecchio et al. 1986). However, justice perceptions only affect LMX if employees attribute justice to their managers (Corporanzo et al. 2002). Heneman et al. (1989: 471) found that employee manager relationships could depend on whether the employee is in the manager's in-group or out-group: “... internal attributions were significantly higher for in group members than for out group members when performance was effective". The researchers also reported that when performance was ineffective, internal attributions were significantly higher for out-group, than in-group members. Bhal (2006) drew on the work by Heneman et al. (1989) and concluded that in situations where supervisors practice differential treatment of subordinate groups, it was more important for these groups to be treated fairly than equally. 
Owing to the fact that there is a tendency for procedures to be enacted by the organization, but implemented by managers, procedural justice perceptions affect reactions toward organizations while interactional justice perceptions affect reactions towards supervisors (Materson et al. 2000). Hence, procedural justice should also affect LMX. Hence, procedural justice should also affect LMX. This view was supported by Manogran et al. (1994) who found a positive relationship between procedural justice and LMX. Flaherty and Pappas (2000), using trust as a proxy for LMX, found salespeople's perceptions of procedural justice affected the level of trust in their managers. The researchers reported that salespeople had greater trust in managers that they believed administered procedures fairly. In addition to procedural and interactional justice, distributive justice was also found to be positively related to LMX (Vecchio et al. 1986). These contentions provide underpinning for hypotheses $\mathrm{H} 2 \mathrm{a}-\mathrm{H} 2 \mathrm{c}$.

H2a: Employees' perceptions of procedural justice are positively related to LMX. H2b: Employees' perceptions of distributive justice are positively related to LMX. H2c: Employees' perceptions of interactional justice are positively related to LMX.

\section{Perceptions of Organizational Justice and $\mathrm{OCB}$}

Employee perceptions of distributive, procedural and interactional justice have been reported in the literature to influence OCB (e.g., Organ 1988; Moorman 1991; Tepper and Taylor 2003). Organ $(1988 ; 1990)$ employed equity theory and Blau's (1964) distinction between economic and social exchange to suggest a theoretical link between distribute justice and OCB. As per equity theory (Adams 1963), if an employee perceives distribution of work rewards relative to work inputs as unfair, and as a consequence, is unhappy, he would be motivated to resolve the tension, which could be achieved through a decreased exhibition of OCB (Organ 1988). Organ (1990) noted that using fairness to promote OCB suggests a contradiction - If OCB is defined as 
behaviour not formally rewarded by an organization, how then could perceptions of distributive justice, which are based on the allocation of rewards, influence OCB. To explain this apparent contradiction, Organ (1990) invoked Blau's (1964) distinction between economic and social exchange and noted that if employees define their relationships with their employers as economic exchanges only, distributive justice will have little, if any, effect on OCB. However, if employees define their relationships with employers as social exchanges, an employee may believe that OCB is an appropriate response to distributive justice even though such behaviour is not directly rewarded.

Procedural justice perceptions have been explained using two components - fairness perceptions and interactional justice (Greenberg 1990). Bies (1987) argued that fair formal procedures, fair interpersonal treatment, or both, may influence procedural justice perceptions. Niehoff and Moorman (1991) however view interactional justice and procedural justice as mutually connected yet separate. Lind and Earley (1992) explained that the role of procedural justice is to enhance distributive justice and that the relationship between procedural justice and OCB could be explained through any effect of distributive justice on OCB. However, a number of researchers have examined the effects of procedural justice on OCB independently vis-à-vis distributive justice (Folger and Konovsky 1989; Moorman 1991). These contentions provide underpinning for $\mathrm{H} 3 \mathrm{a}-\mathrm{H} 3 \mathrm{i}$.

H3a-H3i : Employees' perceptions of procedural, distributive and international justice are positively related to loyalty, compliance and participation OCB respectively.

\section{LMX and job satisfaction}


Many studies conducted on the effect of LMX on job satisfaction found a positive relationship. For example, high quality LMX (Stringer 2006) and supportive managers (Brough and Pearson 2004) were found to be positively related to employee job satisfaction. This was so even in instances of role ambiguity, which was reported to be inversely related to OCB (Podsakoff et al. 2000). One of the reasons attributed to this relationship was owing to the fact that employees with considerate and supportive managers are likely to perceive situations as less ambiguous.

The findings explaining the relationship between LMX and job satisfaction appear to be consistent across different cultural settings. Employees who perceived their managers to be consultative derived more job satisfaction not only in a Western context (Savery 1994) but also in a non-Western context, namely, the United Arab Emirates (Yousef 2000). Similarly, Lok and Crawford (2004) found no significant difference in the impact of leadership style of Hong Kong and Australian managers on job satisfaction. These studies suggest that employees' relationships with their managers contribute to job satisfaction in both Western and non-Western countries. In view of Singapore's common heritage and cultural similarity with Hong Kong, it is expected that Singaporean employee's relationship with their managers will have a positive effect on their job satisfaction. These contentions led to the development of hypothesis 4 .

H4: The quality of employee relationships with their managers (LMX) will positively influence their levels of job satisfaction.

\section{LMX and $O C B$}

Manager's treatment of their employees has been clearly linked to OCB in the literature. Moorman (1991, p.854) noted that “...managers should be concerned with how they treat their employees because employees' perceptions of that treatment could affect the occurrence of 
citizenship behaviour”. Furthermore, Ishak (2005: 8) reported that “...social exchange relationships have an implicit understanding that a history of extra role efforts will, overtime, be recognised, appreciated and rewarded as people seek to reciprocate those who benefit them". OCB could be subordinates' preferred reciprocation means instead of increased productivity as the latter could be constrained by his/her ability, and other external factors such as work schedule and task design (Smith, Organ and Near 1983). This is consistent with an earlier study by Liden and Graen (1980: 464), which reported that the quality of an employee's relationship with his manager to be strongly correlated with “... an employee’s inclination to volunteer for special assignments and to be asked to do extra work in busy situations".

Some researchers suggest that the relationship between LMX and OCB could be indirect. Bhal (2005) found that it is the justice perceptions, in particular procedural and interactional justice, in LMX that affects OCB. Podsakoff et al. (1990) found that a transactional relationship, (i.e. low quality LMX, contingent upon rewards), produces a direct effect on OCB. High quality LMX elicits OCB through trust (Podsakoff et al. 1990). Bolino (1999) suggested that OCB could be “impression enhancing and self-serving" (1999: 82). An employee who performs OCB could be motivated to manage his/her supervisor's impression of him/her, instead of genuine reciprocation. Such motivation could result in employees continuing to perform OCB even in low LMX situation. Notwithstanding Bolino's (1999) view, the following hypothesss (H5a-H5c) are postulated based on previous research into the traditional social exchange definition of LMX. H5a: Employees' relationships with their managers positively influence their loyalty OCB. H5b: Employees' relationships with their managers positively influence their compliance OCB. H5c: Employee's relationships with their managers positively influence their participation OCB. 


\section{Job Satisfaction and $O C B$}

A strong correlation between job satisfaction and OCB has been reported by Bateman and Organ (1983). Williams and Anderson (1991) studied the relationship between OCB, measured in terms of altruism, generalized compliance, and two components of job satisfaction - cognitive and affective. These researchers concluded that the cognitive component significantly predicted both altruism and generalized compliance. Morrison (1994) reported a survey of 317 clerical workers found that employees held differing views of what constituted in-role and extra- role behaviours. Employees were more likely to engage in OCB if they considered that behaviour to be in-role. Isen and Daubman (1984) found that affect influenced cognitive organization. Specifically, individuals with positive affect sorted material into more inclusive categories. This supported the hypothesis that '.. under conditions of positive affect, people tend to see relatedness and interconnections among cognitions, and perhaps process material in a more integrated fashion' (Isen and Daubman 1984: 1212). Moreover, a happy individual is likely to define in-role behaviour more broadly.

Such findings could have been possible because job satisfaction measures tended to include a procedural justice dimension (Organ 1988). When fairness perceptions were isolated from job satisfaction, job satisfaction and OCB were not significantly correlated (Moorman 1991). It is important to note that a study by Schappe (1998) yielded similar results. Schappe provided a plausible explanation for this linkage, reporting that, “... job satisfaction and perceptions of procedural fairness share a common antecedent...", which was not included in the study, and that 'contaminated the relationships of these two variables with OCB' (1998: 287). The study, therefore, recommended that future research include measures of both perceived fairness and job 
satisfaction to clarify their relative effects on OCB. These findings provide underpinning for hypotheses 6a-6c.

H6a: Job satisfaction is positively related to loyalty OCB.

H6b: Job satisfaction is positively related to compliance OCB.

H6c: Job satisfaction is positively related to participation $O C B$.

\section{METHODOLOGY}

\section{Site and Sample}

The site for the study was a public sector organization in Singapore. The organization was undergoing change as part of the PS21 reform. Specifically, the organization was challenged to address three reform initiatives. Firstly the organization's senior leadership was required to move away from a traditional public sector mindset focused on reactive strategy design and implementation to a mindset focused on being more proactive and innovative. The organization identified the senior layers of management that were to undertake specific training measures to bring about this mindset change. A second challenge the organization was facing on account of the PS21 reforms was to change its organizational culture to become more agile with a focus on teamwork and empowerment and to increase overall job satisfaction for staff. The senior management introduced a range of measures which included specific mentoring guidelines to improve the relationship between leaders and subordinates; the heads of work units delegating decision-making responsibility to team members in order to empower them; and a focus on team work and collaboration. These initiatives were also designed to increase job satisfaction. A third challenge was to create a leaner and more accountable organizational structure and to ensure that employees had the necessary skill-sets to focus on creativity, innovation and agility. Specific reform measures to address this challenge were for the senior management to identify how to 
streamline the organization's structure by identifying critical function areas and cutting down on non-critical ones. Once this was done, senior management was tasked with identifying the skills shortages in the critical function areas and developing specific training programs to mitigate the shortage. These three challenges identify the important role of leadership and the critical relationship between leaders and subordinates (assessed through LMX) in order to improve overall job satisfaction in the study organization. Further, organisational justice was identified as an antecedent of LMX. Employees justice perceptions were an important factor in shaping the relationship with their supervisor in a high power distance Singaporean context and therefore critical in this context. In addition, justice perceptions also had a direct impact on the employees' job satisfaction which was an important factor for the study organization. Finally, OCB was included as a study variable as organizational justice and LMX had been reported in the literature to lead to higher levels of OCB which had potential for improvement in work quality. An overall improvement in work quality was essential for the study organization which wanted to adopt a leaner and more accountable structure on account of the PS21 reforms. These three variables along with job satisfaction were designed as a path model in order to investigate the critical relationships between them.

Data were collected through an anonymous survey using questionnaires which were distributed to respondents through the heads of their work units. The questionnaires also included an unmarked return envelope with instructions on how, where and by when to return the completed questionnaires. A memo was circulated to all employees explaining the importance of the study with its practical implications. Staff were encouraged to participate in the study, however it was elucidated that participation was voluntary. A one week deadline was set for staff who participated in the study to return the completed questionnaire in the unmarked return envelope 
and place it specially designated collection boxes. This ensured anonymity of the participants. The heads of work units were instructed to randomly distribute the questionnaires to every third person in their respective work units. A total of 2,200 employees were employed in the organization at the time of the survey and the heads of work units distributed questionnaires to 600 employees randomly. 560 completed questionnaires were returned, resulting in a response rate of 93.3 per cent. The completed questionnaires were collated by a designated head of a work unit after the deadline and then passed on to the principal author. The only other known study reported in this context, namely Ang, Van Dyne and Begley (2003) also had a response rate of 87 percent with Singaporean respondents providing justification to the seriousness with which Singaporean respondents took surveys which had practical implications in terms of better understanding and improvement in work practices.

Respondents were full-time employees in a cross section of positions, with varying management responsibilities. The sample represented approximately 25 percent of the 2,200 employees that were part of the studied organization. A brief demographic profile of the respondents is presented in Table 1. Most of the respondents were male (67.3 percent). A large number of the respondents ( 78.2 percent) were between 25 to 45 years of age. Nearly half of the respondents were in the 25 to 34 age group, and only 9.8 percent were 46 years of age or older. Slightly more than half of the respondents (64.3 percent) had been in the organization for less than 10 years. Nearly half of the respondents had post secondary education. Senior officers in the study organisation had executive level management responsibilities (akin to senior managers) and constituted 23.8 percent of the sample and junior officers who had first line management responsibilities (akin to supervisory managers) represented 76.2 percent of the sample. 
Insert Table 1 about here

\section{Measures, Factor and Reliability Analyses}

All four variables, namely organizational justice, LMX, job satisfaction and OCB were assessed at the individual level. Previously validated instruments were adopted to measure the four variables. Respondents were asked to evaluate a series of statements on a seven point Likert scale ranging from $1=$ 'strongly disagree' to $7=$ 'strongly agree'. Exploratory factor analysis (EFA) was performed using varimax rotation and the factor structure was confirmed using confirmatory factor analysis (CFA) using AMOS. All the AVE (average variance extracted) values except that of job satisfaction were above the 0.05 cut off.

\section{Organizational Justice}

Organizational justice was measured using an 18 item scale adapted from Niehoff and Moorman (1993). The researchers reported organizational justice as a three factor variable - distributive justice (four items), procedural justice (six items), and interactional justice (eight items). EFA for the 18 item scale revealed a two factor structure after the cross-loading items were removed. After CFA was conducted, four items measuring distribute justice (sample items included 'My work schedule is fair' and 'I think that my level of pay is fair') and eight items measuring interactional justice (sample items included 'My supervisor offers adequate justification for decisions made about my job' and 'My supervisor explains very clearly any decision made about my job') were retained with a goodness of fit index (GFI) of $0.987(\mathrm{p}=0.187)$. 


\section{Leader-Member Exchange}

A uni-dimensional 11-item leader member exchange (LMX) instrument, adapted from Liden and Maslyn (1998) was utilised by this study to measure the management of leader subordinate relationship. EFA for the 11 item LMX scale was performed and two items deleted owing to low loading. The items were retained after a CFA was performed with a GFI of $0.994(\mathrm{p}=0.350)$. Sample items included 'I like my supervisor very much as a person' and 'I respect my supervisor's knowledge of and competence on the job'.

\section{Job Satisfaction}

Job satisfaction was measured using an 18-item uni-dimensional scale developed by Brayfield and Rothe (1951), and later used by Moorman (1991). Both these studies adopted a five point Likert scale which was converted by this study to a seven point scale to be consistent with the scales used in assessing the remaining variables. EFA for the 18 item scale was performed and eight items were deleted due to cross-loading. The remaining 10 items were retained after a CFA was performed with a GFI of $0.991(\mathrm{p}=0.310)$. Sample items included 'My job is like a hobby to me' and 'I enjoy my work more than my leisure time'.

\section{Organizational Citizenship Behaviour}

A reduced version of the 34 item scale measuring OCB developed by Van Dyne, Graham and Dienesch (1994) was used by this study. The reduced 23-item scale intended to measure three dimensions of OCB; namely; loyalty, compliance, and participation. The items were subject to EFA. All the items measuring loyalty were removed from the factor structure owing to significant cross-loading and leakage over multiple factors. The two factors of compliance and participation were reduced to a five item (sample items included 'I follow work rules and instructions with 
extreme care' and 'I always come to work on time') and two item (items included 'I do not pursue additional training to improve performance' and 'I have difficulty cooperating with others on projects') scale respectively. These items were confirmed in the CFA with a GFI of $0.999(\mathrm{p}=$ 0.974).

Harman's single factor test was conducted with the items retained after the CFA and tested for common method variance. In line with Podsakoff et al. (2003), the items were subject to an unrotated factor analysis which resulted in six factors with eigenvalues greater than 1.0 with 67.07 per cent of the variance explained by the six factors. The largest factor accounted for 17.71 per cent of the variance. This suggested that the measures were distinct, thus minimising concerns about common method bias (Chen, Aryee and Lee 2005).

\section{RESULTS}

Table 2 shows the descriptive statistics and intercorrelations among the variables in the model.

Insert Table 2 about here

A causal path model was developed to test the hypotheses developed. SmartPLS (Ringle et al. 2005), a form of Partial Least Squares (PLS) modelling was used to analyze the causal relationships (see Figure 1). A common measure of overall model fit in PLS Modelling is the global goodness of fit index (Tennenhause et al. 2005). The global index of 0.46 showed that the model has a large goodness of fit. 
Table 3 shows the results of path analysis which showed that Hypothesis 1 was supported as there were positive and statistically significant paths from Distribute Justice to Job Satisfaction (coefficient $=0.198, \mathrm{t}$-statistic $=4.582, \mathrm{p}<.01)$ and from Interactional Justice to Job Satisfaction (coefficient $=0.142$, t-statistic $=2.009, \mathrm{p}<.01)$. Hypothesis 2 was partially supported as the path leading from Interactional Justice to LMX was positive and statistically significant (coefficient $=0.769$, t-statistic $=23.110, \mathrm{p}<.01$ ). Hypothesis 3 was partially supported as the hypothesized relationship from Distributive Justice to Compliance OCB was positively and statistically significant $($ coefficient $=0.182$, t-statistic $=3.684, \mathrm{p}<.01)$. Hypothesis 4 was supported as the path from LMX to Job Satisfaction was found to be positive and statistically significant (coefficient $=0.329$, t-statistic $=5.290, \mathrm{p}<.01)$. Hypothesis 5 was partially supported as the path from LMX to Compliance OCB was positive and statistically significant (coefficient $=0.262$, $t$ statistic $=3.714, \mathrm{p}<.01)$. The final two paths from Job Satisfaction to Compliance OCB $($ coefficient $=0.283, \mathrm{t}$-statistic $=6.545, \mathrm{p}<.01)$ and from Job Satisfaction to Participation OCB (coefficient $=0.479, \mathrm{t}$-statistic $=8.965, \mathrm{p}<.01)$ were positive and statistically significant thereby supporting Hypothesis 6. The mediation effect of LMX between the two constructs of organizational justice and the two constructs of OCB was calculated using Sobel's test (Preacher and Hayes 2008). The analysis showed that LMX mediates the path from Interactional Justice to Compliance OCB (t-statistic $=3.667, \mathrm{p}=0.0002)$.

Insert Table 3 about here

\section{DISCUSSION}

The main aim of this study is to examine the performance outcomes of Singapore public sector employees such as job satisfaction and OCB, as influenced by perceptions of organizational 
justice and their relationship with their superiors (LMX). Consistent with the intention of Singapore's PS21 reform, there was support for the positive effect of LMX in the development of subordinates' OCB. Our study showed that organizational justice had a significant positive impact on job satisfaction and LMX, while LMX significantly contributed positively towards both, job satisfaction and OCB. Moreover, job satisfaction had a positive impact on employees OCB. It was also noted that LMX acted as a mediator between organisational justice perceptions and $\mathrm{OCB}$.

The CFA results for the two-factor variables of organizational justice perceptions and OCB confirmed the EFA results and indicated that Western developed instruments has sound psychometric soundness in an Eastern Singaporean context. Organizational justice perceptions were treated as a two factor structure of distributive and interactional justice, with the items measuring procedural justice not included owing to poor factor loadings which was in contrast to Niehoff and Moorman (1993) who found organizational justice to comprise of three distinct and inter-related factors. Thus, the Singaporean public sector employees in the study organisation viewed fairness from the perspectives of distributive and interactional justice. LMX and job satisfaction scales were validated as unidimensional constructs by this study, in line with Liden and Maslyn (1998) and Brayfield and Rothe (1951) respectively.

The CFA results for OCB revealed a two factor structure, contrary to the three factor structure as reported by Van Dyne, Graham and Dienesch (1994) in the Singaporean context. This finding was attributed to the study organisation who reported OCB having two sub-components, namely, compliance and participation. This finding can be explained by the underlying culture of the public sector agency in the current study as it requires its employees to be compliant and 
demonstrate active participation in their extra role behaviours. These two behaviours are important as public sector organizations in Singapore subject to PS21 reforms are expected to create a more decentralized and empowered workforce (Lee and Haque 2006).

The study findings supported the impact of employees' perceptions of organisational justice on the level of their job satisfaction. In particular, distributive and interactional justice had a positive impact on the job satisfaction as public sector managers are given more responsibilities, for instance, to be more responsible for the pay structures and employment conditions of their subordinates. Employees had an expectation that the manner in which outcomes are distributed and workloads allocated in the public sector organization were an indicator of distributive fairness, which ultimately reflected onto their level of comfort in continuing in the organization. These findings were in line with Fischer (2004) who found positive relationships between perceptions of distributive justice and job satisfaction. Moreover, interactional fairness, that is, the interpersonal sensitivity with which an individual is treated and the sincerity with which procedures are applied in decision making also contributed to their overall levels of satisfaction and ultimately their commitment to the organisation. This finding supports those of Lambert (2003) who found a similar positive relationship with correctional staff in the United States.

Interactional justice perceptions were positively related to LMX. Singaporean public sector employees viewed interactional justice perceptions as important in shaping their relationship with their superiors during the implementation of various public sector reform initiatives. Trust as a justice measure plays a vital role and has known to influence LMX (Flaherty and Pappas 2000). Employees' perceptions of fairness, highlighted through the levels and interactional justice imparted by their superiors assists in the development of trust, thereby impacting on LMX. In a 
high context, high power distance society like Singapore where trust is an important element in fostering relationships (Hofstede 1980), it is contended that employees view justice perceptions through the lens of trust, which ultimately affects the relationship with their superiors. Employees who perceive fairness in the workplace develop a sense of trust with their managers and have high quality interactions with them.

With respect to the relationship between organizational justice and $\mathrm{OCB}$, the results indicated that only distributive justice perceptions were significantly related to compliance OCB. The findings suggested that fairness perceptions resulted in increased compliance and obedience among employees. Podsakoff et al. (1990) found that LMX influences OCB through trust that employees have in their managers and was of the view that fairness perceptions is a determinant of trust and recommended that future research examine this possibility. The findings suggested that LMX had a mediating effect between interactional justice and compliance OCB. This confirmed the results from Materson et al. (2000) who found a similar relationship with public university employees. This was attributed to trust developed between subordinates and managers owing to fairness perceptions (interactional justice) which ultimately results in positive relationships between them. Moreover, the positive LMX impacts on employees' compliance OCB through higher levels of commitment shaped by increased participation.

In this study, LMX was found to have a positive impact on public sector employees' job satisfaction. This finding suggests that employees who experienced a favourable relationship with their managers are more satisfied than employees who do not enjoy high quality exchanges with their superiors. This finding was consistent with Yousef (2000) who found a similar result with a sample of private and public sector organizations in the UAE. Moreover, job satisfaction had a 
positive relationship on both compliance and participation OCB (Bateman and Organ 1983). These two findings reinforced the impact of positive leader-subordinate relationships to promote a satisfied public sector workforce, who are more willing to exhibit positive citizenship behaviours in organisations which are experiencing intensifying workload due to PS21 reforms.

The study findings have a number of theoretical and practical implications. From a theoretical point of view, firstly, the study develops the four variables - organisational justice, job satisfaction, LMX and OCB into a framework (Figure 1) as per LMX theory in a Singapore public sector context, thereby adding to the existing literature. LMX theory as a theoretical frame provides the lens to empirically assess the linkages between organisational justice, job satisfaction and OCB. Second, the study confirms the theoretical linkages presented in Figure 1 in a Singapore public sector setting, thereby providing an empirical assessment of LMX theory (Dienesch and Liden 1986; Graen and Uhl-Bien 1995; Lee 2005; Wang et al. 2005) in a relatively untested national context. While only one other study reported in the literature, namely Ang, et al.(2003) has empirically assessed linkages between organisational justice, job satisfaction and OCB, there is no reported study empirically assessing LMX theory in this context. Third, the findings suggest that organisational justice and OCB were treated by the respondents as a twofactor structure in contrast with the empirical findings in Western contexts where they were reported as comprising of three factors each, as explained earlier. Future researchers are encouraged to empirically assess the validity of these constructs across other public sector organisations in Singapore to confirm our findings.

From a practical perspective, one of the main findings of our study was the role of LMX in fostering increased levels of job satisfaction and OCB. In a society which values relationship 
building (Hofstede 1980), it becomes imperative for Singaporean managers to engage in high quality exchanges with their subordinates, especially as the organisation is in the process of undergoing PS21 type organisational reform initiatives. This in turn encourages employees to do more than their fair share and demonstrate willingness to go the extra mile through their OCB. With PS21 reform (Cheung and Scott 2003; Lee and Haque 2006) these interactions assist in developing leaner and more accountable organizational structures by identifying downsizing initiatives, similar to the one the study organization was facing. It also ensures corporate knowledge is retained post change. Secondly, we contend that the importance of fostering OCB through LMX can be an avenue for leveraging better relational connections and performance. With a number of changes to the employment landscape with various reforms around greater flexibility to public sector employees (e.g. working from remote locations) being implemented by the Singapore Government (Ministry of Manpower 2005; 2006) subordinates in contemporary public sector organizations in Singapore might be challenged to maintain contact with their supervisor remotely, which further underpins the importance of high quality exchanges between supervisor and subordinate. As Singaporean public sector agencies continue to implement more PS21 type reforms, there is an increasing need for effective leadership in the pursuit of transforming itself from a bureaucratic to a more dynamic organizational culture.

\section{Limitations of the Study}

While the data were collected from a single source at one point in time, we conducted a Harmon's one factor test (Podsakoff et al. 2003) to check for common method bias. The analysis showed that common method bias is not a concern in the current study. The scales employed in this study met or exceeded the minimum required standards of psychometric soundness. Nevertheless, it should be noted that data was collected from one public sector organization in 
Singapore. While a number of studies in the public sector domain have reported findings based on data from one organization (e.g. Waterhouse and Lewis 2004; Hunt and Ivergard 2007; Noblet and Rodwell 2009a; Noblet and Rodwell 2009b; Rodwell et al. 2009), collecting longitudinal data as well as data from multiple public sector organizations in Singapore will add to the generalizability of the study findings. Moreover, Singaporean society is not culturally monolithic. Singapore is predominantly Chinese with lesser representations from the Malaysian and Indian communities with contribution from a range of Western nations. The employment of the study scales in other countries with other cultural compositions may attract alternative sets of instrument-item combinations. Hence, there is merit in administering the questionnaire scales in not only other types of organizations, but also in different national contexts to evaluate the generalisability of the measures.

\section{CONCLUSION}

The intensification of the organisational change within the public sector is seeing a strengthening of individual voluntarily engagement in extra role behaviours. These forces have led to a growing importance in the role of LMX and OCB in this context. However the emergence of the stream of LMX and OCB within the management literature is more pronounced and embedded in Western frameworks. This study is an attempt to fill this gap in the literature and empirically test some of the important variables and their connections that can lead to the manifestation of LMX and OCB in a Singaporean public sector context.

In conclusion, with the ongoing reform in the Singapore public sector, our findings suggest that the quality of the relationship between employees and their supervisors is vital to achieve some of the objectives of organisational change, especially around the issue of downsizing and creating 
leaner, meaner and more accountable public sector organizations. As a result of their perceptions of organizational justice and high level exchanges with their supervisors, these public sector employees reported positively in their willingness to exhibit positive OCB and ultimately, increased satisfaction levels with their job in this era of on-going public sector reform. Hence, this finding reflects the importance of focusing on building quality relationships between leaders and their followers as an antecedent to OCB in public sector organizations in Singapore.

\section{REFERENCES}

Ackroyd, S., Kirkpatrick, I. and Walker, R. (2007) Public Management Reform in the UK and its Consequences for Professional Organization: A Comparative Analysis. Public Administration, 85:1 pp 9-26.

Adams, J.S. (1963) Wage Inequities, Productivity, and Work Quality. Industrial Relations, 3:pp 9-16.

Ang, S., Van Dyne, L. and Begley, T.M. (2003) The Employment Relationships of Foreign Workers versus Local Employees: A Field Study of Organizational Justice, Job Satisfaction, Performance and OCB. Journal of Organizational Behaviour, 24:pp 561-583.

Aryee, S. and Chay, Y.W. (2001) Workplace Justice, Citizenship Behavior, and Turnover Intentions in a Union Context: Examining the Mediating Role of Perceived Union Support and Union Instrumentality. Journal of Applied Psychology, 86:pp 154-160.

Batemen, T.S. and Organ, D.W. (1983) Job Satisfaction and Good Soldier: The Relationship Between Affect and "Citizenship". Academy of Management Journal, 26:pp 587-595.

Bhal, K.T. (2006) LMX-citizenship Behaviour Relationship: Justice as a Mediator. Leadership and Organization Development Journal, 27:2 pp 106-117. 
Bies, R.J. (1987) The Predicament of Injustice: The Management of Moral Outrage. In L.

L.Cummings and B. M. Staw eds. Research in Organizational Behavior, 9:289-319.

Greenwich, CT: JAI Press.

Blau, P. (1964) Exchange and Power in Social Life, New York: Wiley.

Bolino, M.C. (1999) Citizenship and Impression Management: Good Soldiers or Good Actors? Academy of Management Review 24:1 pp 82-98.

Brayfield, A.H. and Rothe, H.F. (1951) An Index of Job Satisfaction. Journal of Applied Psychology, 35:5 pp 307-311.

Brough, P. and Pearson, J. (2004) Evaluating the Influence of the Type of Social Support on Job Satisfaction and Work Related Psychological Well Being. International Journal of Organization Behaviour, 8:2 pp 472-485.

Brunetto, Y., Farr-Wharton, R. and Shacklock, K. (2010) The impact of supervisor-subordinate relationships on morale: Implications for public and private sector nurses' commitment. Human Resource Management Journal, 20:2 pp 206-225.

Chen, Z.X., Aryee, S and Lee, C. (2005) Test of a mediation model of perceived organizational support', Journal of Vocational Behavior, 66:pp 457-470.

Cheung, A.B.L. and Scott, I (2003) Governance and Public Sector Reform in Asia: Paradigm Shifts or Business as Usual? London: Routledge Curzon.

Commonwealth Secretariat. (1998) Current Good Practices and New Developments in Public Service Management: A Profile of the Public Service of Singapore. The Public Service Country Profile Series No. 8, London, Commonwealth Secretariat.

Corporanzo, R., Prehar, C.A. and Chen, P.Y. (2002) Using Social exchange theory to distinguish procedural from interactional justice. Group and Organization Management, 27:3 pp 324351. 
Coyle-Shapiro, J. (2002) A psychological contract perspective of organizational citizenship behaviour. Journal of Organizational Behaviour, 23:8 pp 927-946.

Coyle-Shapiro, J.A.M. and Kessler, I. (2003) The employment relationship in the u.k. public sector: A psychological contract perspective. Journal of Public Administration Research and Theory, 13:pp 213-230.

Crouch, A. and Yetton, P. (1988) Manager-subordinate dyads: Relationships among task and social contact, manager friendliness, and subordinate performance in management groups. Organizational Behavior and Human Decision Processes. 4:pp 65-82.

Dansereau, F., Graen, G. and Haga, W. (1975) A Vertical Dyad Approach to Leadership Within Formal Organizations. Organizational Behaviour and Human Performance, 13: pp 46-78.

Dienesch, R.M. and Liden, R.C. (1986) Leader-Member Exchange Model of Leadership: A Critique and Further Development. Academy of Management Review, 11:pp 618-634.

Engle, E.M. and Lord, R.G. (1997) Implicit theories, self-schemas, and leader-member exchange. Academy of Management Journal, 40:4 pp 988-1010.

Erdogan, B. and Enders, J. (2007) Support from the top: supervisors' perceived organizational support as a moderator of leader-member exchange to satisfaction and performance relationships. Journal of Applied Psychology. 92:2 pp 321-330.

Erdogan, B., Liden, R.C. and Kraimer, M.L. (2006) Justice and leader-member exchange: The moderating role of organizational culture. Academy of Management Journal. 49:2 pp 395406.

Fischer, R. (2004) Rewarding employee loyalty: An organizational justice approach. International Journal of Organizational Behaviour, 8:3 pp 486-503.

Flaherty, K.E. and Pappas, J.M. (2000) The Role of Trust in Salesperson-Sales Manager Relationships. Journal of Personal Selling and Sales Management, 20:4 pp 271-278. 
Folger, R. and Corporanzo, R. (1998) Organizational Justice and Human Resource Management. Thousand Oaks, CA: Sage.

Folger , R. and Konovsky M.A. (1989) Effects of Procedural and Distributive Justice on Reaction to Pay Raise Decisions. Academy of Management Journal, 32:pp 115-130.

Graen, G.B. (1976) Role making processes within complex organization. In Dunnette, M.D. (Ed.), Handbook of Industrial and Organizational Psychology, Chicago, IL: Rand-McNally, pp. 1201-45.

Graen, G. and Uhl-Bien, M. (1995) Relationship-based Approach to Leadership: Development of Leader-Member Exchange (LMX) Theory of Leadership over 25 years: Applying a Multilevel Multi-domain Perspective. Leadership Quarterly, 6:2 pp 219-247.

Greenberg, J. (1990) Organizational Justice: Yesterday, Today, and Tomorrow. Journal of Management, 16:pp 399-432.

Greenberg, J. (1987) A Taxonomy of Organizational Justice Theories. Academy of Management Review, 12:pp 9-22.

Gerstner, C. and Day, D. (1997) Meta-analytic Review of Leader-Member Exchange Theory: Correlates and Construct Issues. Journal of Applied Psychology, 82:pp 827-844.

Heneman, R.L., Greenberger, D.B. and Anonyuo, C. (1989) Attributions and Exchanges: The Effects of Interpersonal Factors on the Diagnosis of Employee Performance. Academy of Management Journal, 32:pp 466-476.

Hofstede, G.H. (1980) Culture's Consequences: International Differences in Work-Related Values, Thousand Oaks, CA: Sage.

House, R.J., and Associates eds. (2004) Culture, Leadership, and Organizations: The GLOBE Study of 62 Societies, Thousand Oaks, CA: Sage. 
Hunt, B. and Ivergard, T. (2007) Organizational Climate and Workplace Efficiency: Learning from Performance Measurement in a Public-Sector Cadre Organization. Public Management Review, 9:1 pp 24-47.

Isen, A.M. and Daubman, K.A. (1984) The Influence of Affect on Categorization. Journal of Personality and Social Psychology, 47:pp 1206-1217.

Ishak, N.A. (2005) Promoting Employees’ Innovativeness and Organizational Citizenship Behaviour through Superior-Subordinate Relationship in the Workplace. Research and Practice in Human Resource Management, 13:2 pp 16-30.

Lambert, E. (2003) The Impact of Organizational Justice on Correctional Staff. Journal of Criminal Justice, 31:2 pp 155-168.

Lee, E.W.Y. and Haque, M.S. (2006) The New Public Management Reform and Governance in Asian NICs: A Comparison of Hong Kong and Singapore. Governance-An International Journal of Policy and Administration, 19:4, pp 605-626.

Lee, J. (2005) Effects of Leadership and Leader-Member Exchange on Commitment. Leadership and Organization Development Journal, 26:7/8 pp 655-672.

Liang, S.K., Ling, H.C., and Hsieh, S.Y. (2007) The Mediating Effects of Leader-Member Exchange Quality to Influence the Relationships Between Paternalistic Leadership and Organizational Citizenship Behaviors. Journal of American Academy of Business, 10:pp 127137.

Liden, R.C. and Maslyn, J.M. (1998) Multidimensionality of Leader-Member Exchange: An Empirical Assessment through Scale Development. Journal of Management, 24:1 pp 43-72. Liden, R.C. and Grean, G.B. (1980) Generalizability of the Vertical Dyad Linkage Model of Leadership. Academy of Management Journal, 23:3 pp 451-465. 
Lind, E. A. and Earley, P. C. (1992) Procedural Justice and Culture. International Journal of Psychology, 27:2 pp 227-242.

Lim, S. G. (1998) PS21: Gearing up the public service for the $21^{\text {st }}$ century. In: A. Mahazinan and T. Y. Lee (eds), Singapore: Re-engineering Success (Chapter 12, pp. 124 - 131). Singapore: Oxford University Press.

Lok, P. and Crawford, J. (1994) The Effect of Organizational Culture and Leadership Style on Job Satisfaction and Organizational Commitment. Journal of Management Development, 23:3/4 pp 321-338.

Manogran, P., Stauffer, J. and Conlon, E.J. (1994) Leader-member exchange as a key mediating variable between employees' perception of fairness and employee citizenship behaviour. National Academy of Management Meeting Proceedings. Dallas, Texas.

Materson, S.S., Lewis, K., Golmand, B.M. and Taylor, M.S. (2000) Integrating Justice and Social Exchange: The Differing Effects of Fair Procedures and Treatment on Work Relationships. Academy of Management Journal, 43:4 pp 738-748.

Ministry of Manpower (2005) Work-life harmony report - Findings and recommendations for employers on how to use work-life strategies to optimize business performance. Singapore: Quality Workplace Department.

Ministry of Manpower (2006) Labour market, Second Quarter 2006. Singapore: Manpower Research and Statistics Department.

Moorman, R.H. (1991) Relationship Between Organizational Justice and Organizational Citizenship Behaviours: Do Fairness Perceptions Influence Employee Citizenship? Journal of Applied Psychology, 76:6 pp 845-855. 
Morrison, E.W. (1994) Role Definitions and Organizational Citizenship Behaviour: The Importance of the Employee's Perspective. Academy of Management Journal, 6:3 pp 15431567.

Niehoff, B.P. and Moorman, R.H. (1993) Justice as a Mediator of the Relationship between Methods of Monitoring and Organizational Citizenship Behaviour. Academy of Management Journal, 36:3 pp 527-556.

Noblet, A. and Rodwell, J.J. (2009a) Integrating Job Stress and Social Exchange Theories to Predict Employee Strain in Reformed Public Sector Contexts. Journal of Public Administration Research and Theory, 19:3 pp 555-578

Noblet, A. and Rodwell, J.J. (2009b) Identifying the Predictors of Employee Health and Satisfaction in an NPM Environment: Testing a Comprehensive and Non-linear DemandControl-Support Model. Public Management Review, 11:5 pp 663-683

OECD (2010) Public Administration after "New Public Management: Value for Money in Government. OECD Publishing.

Ong, P. (2010) Role of PS21 and Leadership in Supporting Public Service productivity. Speech at the PS21 ExCEL Convention Forum, 02 Nov 2010, Singapore.

Organ, D.W. (1988) A Re-statement of the Satisfaction-Performance Hypothesis. Journal of Management, 14:4 pp 547-557.

Organ, D.W. (1990) The Motivational Basis of Organizational Citizenship Behavior. Research in Organizational Behavior, 12:pp 43-72.

Organ, D.W. and Konovsky, M. (1989) Cognitive Versus Affective Determinants of Organizational Citizenship Behaviour. Journal of Applied Psychology, 74:1 pp 157-164. Osborne, D. and Gaebler, T (1992) Reinventing Government: How the Entrepreneurial Spirit is Transforming the Public Sector. Reading, MA: Addison-Wesley. 
Parry, K.W. (2003) Leadership, Culture and Performance: The Case of the New Zealand public Sector. Journal of Change Management, 4: pp 376-99.

Pellegrini, E.K. and Scandura, T.A. (2006) Leader-member exchange (Lmx), paternalism, and delegation in the Turkish business culture: An empirical investigation. Journal of International Business Studies. 37:2 pp 264-279.

Petty, M.M., McGee, G.W. and Cavender, J.W. (1984) A Meta-Analysis of the Relationships Between Individual Job Satisfaction and Individual Performance. Academy of Management Review, 9:4 pp 712-721.

Preacher, K.J., and Hayes, A.F. (2008) Asymptotic and Resampling Strategies for Assessing and Comparing Indirect Effects in Multiple Mediator Models. Behavior Research Methods, 40:pp 879-891.

Podsakoff, P.M., MacKenzie,S.B., Lee, J.Y., and Podsakoff, N.P. (2003) Common Method Biases in Behavioral Research: A Critical Review of the Literature and Recommended Remedies. Journal of Applied Psychology, 88:5 pp 879-903.

Podsakoff, P., Mackenzie, S., Paine, B. and Bachrach, D. (2000) Organizational Citizenship Behaviour: A Critical Review of the Theoretical and Empirical Literature and Suggestions for Future Research. Journal of Management, 26:3 pp 513-563.

Podsakoff, P.M., MacKenzie, S.B., Moorman, R.H., and Fetter, R. (1990) Transformational Leader Behaviours and Their Effects on Followers' Trust in Leader, Satisfaction and Organisational Citizenship Behaviours. Leadership Quarterly, 1:2 pp 107-142.

Pollitt, C. (1993) Managerialism and the Public Services, 2nd edn. Blackwell, Oxford, UK. PS 21 (2010) PS21: Be the Change, Prime Ministers Office, Singapore Government, Singapore (http://www.ps21.gov.sg/rationale.html).

Ringle, C.M., Wende, S., and Will, A. (2005) SmartPLS 2.0 (beta). Hamburg: www.smartpls.de 
Rodwell, J.J., Noblet, A.J., Steane, P.D., Osborne, S. and Allisey, A. (2009) Investigating People Management Issues in a Third Sector Health Care Organisation: An Inductive Approach. Australian Journal of Advanced Nursing, 27:2 pp 55-62.

Rubin, E.V. (2007) The Role of Procedural Justice in Public Personnel Management: Empirical Results from the Department of Defense. Journal of Public Administration Research and Theory, 19:pp 125-143.

Samaratunge, R., Alam, Q., and Teicher, J. (2008) Public Sector Reforms and Accountability: The Case of South and Southeast Asia. Public Management Review, 10:pp 101-126.

Savery, L.K. (1994) Attitudes to Work: The Influence of Perceived Styles of Leadership on a Group of Workers. Leadership and Organization Development Journal, 15:4 pp 12-18.

Saxena, N.C. (2011) Virtuous Cycles: The Singapore Public Service and National Development. United Nations Development Programme.

Scandura, T.A. and Graen, G.B. (1984) Moderating effects of initial leader-member exchange status on the effects of a leadership intervention. Journal of Applied Psychology. 69:pp428436.

Schappe, S. (1998) The Influence of Job Satisfaction, Organizational Commitment and Fairness Perceptions on Organizational Citizenship Behaviour. Journal of Psychology, 132:3 pp 227290.

Skarlicki, D.P and Folger, R (1997) Retaliation in the Workplace: The Roles of Distributive, Procedural, and Interactional Justice. Journal of Applied Psychology, 82:3 pp 434-443.

Skarlicki, D., and Latham, G. 1996. Increasing Citizenship Behavior within a Labor Union: A Test of the Organizational Justice Theory. Journal of Applied Psychology, 81:pp 161-9.

Smith, C.A., Organ, D.W. and Near, J.P. (1983) Organizational Citizenship Behaviour: Its Nature and Antecedents. Journal of Applied Psychology, 68:pp 653-663. 
Stringer, L. (2006) The Link between the Quality of the Supervisor-Employee Relationship and the Level of the Employee's Job Satisfaction. Public Organization Review, 6:2 pp 125-142.

Teagarden, M.B. and Von Glinow, M.A. (1997) Human Resource Management in Cross-Cultural Contexts: Emic Practices versus Epic Philosophies. Management International Review, 37:1 pp 7-20.

Tennenhause, M., Vinzi, V.E., Chatelin, Y.M., and Lauro, C. (2005) PLS Path Modeling. Computational Statistics and Data Analysis, 48:pp 159-205.

Tepper, B.J. and Taylor, E.C. (2003) Relationships among supervisors' and subordinates' procedural justice perceptions and organizational citizenship behaviors. Academy of Management Journal, 46:pp 97-105.

Van-Dyne, L., Graham, J.W. and Dienesch, R.M. (1994) Organizational Citizenship Behaviour: Construct Redefinition, Measurement, and Validation. Academy of Management Journal, $37: 4$ pp $765-802$.

Vecchio, R.P., Griffeth, R.W. and Hom, P.W. (1986) The Predictive Utility of Vertical Dyad Linkage Approach. Journal of Social Psychology, 126:5 pp 617-25.

Vigoda-Gadot, E. (2007) Leadership Style, Organizational Politics, and Employees’ Performance: An Empirical Examination of Two Competing Models. Personnel Review, 36:5 pp 661-683.

Vigoda, E. and Cohen, A. (2003) Work Congruence and Excellence in Human Resource Management Empirical Evidence From the Israeli Nonprofit Sector. Review of Public Personnel Administration, 23:3 pp 192-216.

Vigoda, E. (2000) Internal Politics in Public Administration Systems: An Empirical Examination of its Relationship with Job Congruence, Organizational Citizenship Behavior and In-role Performances. Public Personnel Management, 29:pp 185-210. 
Wang, H., Law, K.S., Hackett, R.D., Wang, D. and Chen, Z.X. (2005) Leader-member exchange as a mediator of the relationship between transformational leadership and followers' performance and organizational citizenship behaviour. Academy of Management Journal, 48: pp 420-32.

Waterhouse, J. and Lewis, D. (2004) Communicating Culture Change: HRM Implications for Public Sector Organizations. Public Management Review, 6:3 pp 353-376.

Wharton, R., Potter, P. and Parry, L.E. (2004) Keeping the Faculty: Issues of Socialization, Justice, and Commitment in the Workplace. Journal of Behavioural and Applied Management, September, 6:1 pp 4-20.

Williams, L.J. and Anderson, S.E. (1991) Job Satisfaction and Organizational Commitment as Predictors of Organizational Citizenship and In-role Behaviours. Journal of Management, September, 17:3 pp 601-617.

Yeung, A.K. and Ready, D.A. (1995) Developing Leadership Capabilities of Global Corporations: A Comparative Study in Eight Nations, Human Resource Management, 34:4 pp 529-547.

Yiannouka, S.N. (2011) Redesigning the Public Service for the 21st Century: The Singapore Experience. 20 Oct 2011, Academy of Public Administration. Astana, Kazakhstan (http://www.spp.nus.edu.sg/docs/fac/Speeches\%20Given/Redesigning\%20the\%20Public\%20 Service\%20for\%20the\%2021st\%20Century.pdf, accessed 27 Feb 2013).

Yousef, D.A. (2000) Organizational Commitment: A Mediator of the Relationship of Leadership Behaviour with Job Satisfaction and Performance in a Non-Western Country. Journal of Managerial Psychology, 15:1 pp 6-24. 
FIGURE 1 A Conceptual Framework of Organizational Citizenship Behaviour in Singapore

Public Sector Agency

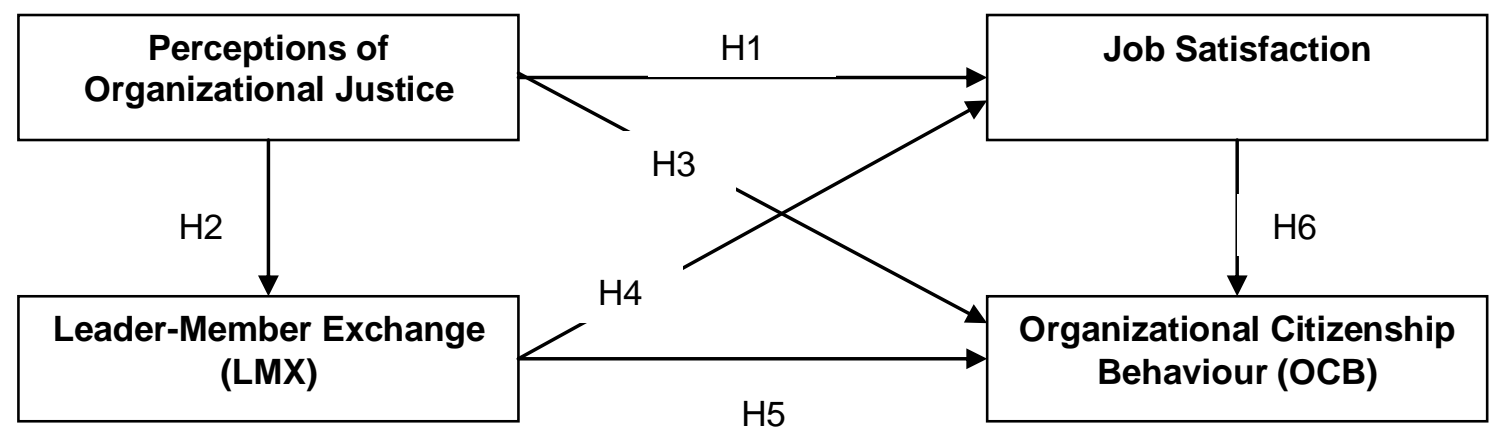


TABLE 1: Demographic Profile of Respondents $(\mathrm{N}=560)$

\begin{tabular}{|c|c|c|c|}
\hline Gender & $\%$ & Level in the Organization & $\%$ \\
\hline Male & 67.3 & Senior Officers & 23.8 \\
\hline Female & 32.7 & Junior Officers & 76.2 \\
\hline Age (in years) & & Years in Service & \\
\hline Less than 25 & 12.0 & Less than 5 & 31.3 \\
\hline $25-34$ & 49.6 & 5 to 10 & 33.0 \\
\hline $35-45$ & 28.6 & 11 to 15 & 14.1 \\
\hline 46 and above & 9.8 & 16 or more & 21.6 \\
\hline \multicolumn{4}{|l|}{ Education } \\
\hline Below 5 ‘O’ Level & 32.1 & & \\
\hline 5 'O' Level or more & 18.4 & & \\
\hline Diploma/'A' Level & 25.9 & & \\
\hline Degree & 23.6 & & \\
\hline
\end{tabular}


Table 2: Descriptive Statistics and Intercorrelations

\begin{tabular}{|c|c|c|c|c|c|c|c|c|c|}
\hline Variables & Mean & s.d. & AVE & 1 & 2 & 3 & 4 & 5 & 6 \\
\hline $\begin{array}{l}\text { Distributive } \\
\text { Justice }\end{array}$ & 5.21 & 0.97 & 0.71 & $(0.90)$ & & & & & \\
\hline $\begin{array}{l}\text { Interactional } \\
\text { Justice }\end{array}$ & 5.42 & 0.9 & 0.82 & $.57 * *$ & $(0.97)$ & & & & \\
\hline LMX & 5.43 & 0.92 & 0.65 & $.42 * *$ & $.75 * *$ & $(0.88)$ & & & \\
\hline $\begin{array}{l}\text { Job } \\
\text { Satisfaction }\end{array}$ & 5.05 & 0.93 & 0.44 & $.42 * *$ & $.50 * *$ & $.50 * *$ & $(0.94)$ & & \\
\hline $\begin{array}{l}\text { Compliance } \\
\text { OCB }\end{array}$ & 5.78 & 0.76 & 0.57 & $.39 * *$ & $.41 * *$ & $.46 * *$ & $.49 * *$ & $(0.87)$ & \\
\hline $\begin{array}{l}\text { Participation } \\
\text { OCB }\end{array}$ & 5.65 & 1.07 & 0.74 & $.15 * *$ & $.21 * *$ & $.19 * *$ & $.44 * *$ & $.26 * *$ & $(0.85)$ \\
\hline
\end{tabular}

Note: $* * \mathrm{p}<0.01$

Values in parentheses are composite reliabilities.

s.d. = standard deviation; $\mathrm{AVE}=$ average variance extracted 
TABLE 3: Results of Path Analysis

\begin{tabular}{|c|c|c|c|c|}
\hline Hypothesis & Paths & Path Coefficients & t-statistic & Sig. level \\
\hline H1a & Distributive Justice $\rightarrow$ Job Satisfaction & 0.20 & 4.58 & $* *$ \\
\hline $\mathrm{H} 1 \mathrm{~b}$ & Interactional Justice $\rightarrow$ Job Satisfaction & 0.14 & 2.01 & $*$ \\
\hline $\mathrm{H} 2 \mathrm{a}$ & Distributive Justice $\rightarrow$ LMX & -0.02 & 0.51 & n.s. \\
\hline $\mathrm{H} 2 \mathrm{~b}$ & Interactional Justice $\rightarrow$ LMX & 0.77 & 23.11 & $* *$ \\
\hline $\mathrm{H} 3 \mathrm{a}$ & Distributive Justice $\rightarrow$ Compliance OCB & 0.18 & 3.68 & $* *$ \\
\hline $\mathrm{H} 3 \mathrm{~b}$ & Interactional Justice $\rightarrow$ Compliance OCB & -0.02 & 0.25 & n.s. \\
\hline $\mathrm{H} 3 \mathrm{c}$ & Distributive Justice $\rightarrow$ Participation OCB & -0.04 & 0.83 & n.s. \\
\hline $\mathrm{H} 3 \mathrm{~d}$ & Interactional Justice $\rightarrow$ Participation OCB & 0.04 & 0.07 & n.s. \\
\hline $\mathrm{H} 4$ & LMX $\rightarrow$ Job Satisfaction & 0.33 & 5.29 & $* *$ \\
\hline H5a & LMX $\rightarrow$ Compliance OCB & 0.26 & 3.71 & $* *$ \\
\hline $\mathrm{H} 5 \mathrm{~b}$ & LMX $\rightarrow$ Participation OCB & -0.06 & 0.84 & n.s. \\
\hline H6a & Job Satisfaction $\rightarrow$ Compliance OCB & 0.28 & 6.54 & $* *$ \\
\hline $\mathrm{H} 6 \mathrm{~b}$ & Job Satisfaction $\rightarrow$ Participation OCB & 0.48 & 8.96 & $* *$ \\
\hline
\end{tabular}

Note: $\mathrm{N}=560$

n.s. $=$ not significant

$* p<.05 ; * * p<.01$ 